\title{
VJ em cena: espaços como partitura audiovisual
}

\section{Patricia Moran}

\begin{abstract}
Resumo
Vamos discutir neste artigo projeções de imagens manipuladas ao vivo que funcionam como partituras audiovisuais. São cintilação: imagens figurativas e gráficas, pessoas dançando sob luzes estroboscópicas. Na noite, em boates, raves e galerias, a distribuição das telas no lugar e 0 excesso de luzes coloridas criam o espaço-experiência, o espaço-estimulo, criam projeçōes-espaço. O espaço de estimulos aqui proporcionados promove-uma experiência imersiva que se aproxima de outros dispositivos com imagens-espaço, como os ambientes dos videogames e da realidade virtual interativa. Por outro lado, deles se afastam por se constituirem de imagens-luz, de imagens cintilantes figurativas ou não, enfim, por se estruturarem como partituras audiovisuais.
\end{abstract}

Palavras-chave: VJ, Manipulação de imagens ao vivo, Espaço, Partitura Audiovisual

\section{Abstract}

We are going to discuss in this article the projection of manipulated live images which double as audiovisual scores. Sparkles would be: figurative and graphic images, people dancing under strobe lights. At night, in nightclubs, raves and malls, the distribution of screens and the excess of colored lights create experience/space, stimuli/space, create projections/ space. The space stimuli presented here promote an inverse experience which approaches other image/space devices, such as the environments found in videogames and interactive virtual reality. On the other hand, they also pull away since they are made up of imageflight, of sparkling figurative images or not, in sum, for being structured as audiovisual scores.

Key words: VJ, Manipulated live images, Space, Audiovisual Score.

\footnotetext{
- Professora do Programa de Pós-Graduação em Comunicação Social da Universidade Federal de Minas Gerais. Desenvolve pesquisa sobre a poetica dos Vjs intitulada: A Metáfora dos Sentidos. Realizadora de filmes de ficção, de documentários e de videos experimentais. Provou o vjing e gostou.
} 
Somos qualquer coisa que se passa no intervalo de um

espetáculo.

Fernando Pessoa ${ }^{1}$

\section{Nomes: Filiação e Processo}

VJ. Uma sigla para diversos nomes. Desdobrada fala de caminhos expressivos para uma poética. No exercício dos próprios VJs se auto-definirem e buscarem uma conceituação para o Vjing colocam-se em jogo maneiras de se criar, de se produzir representações. Buscar as representações produzidas extrapola o exercício classificatório confortànte, trata-se de pensar a poética do vjing na acepção de Umberto Eco através de Paul Valéry, ou seja, uma leitura poética implica a 'análise da estrutura da obra, de sorte que da maneira como a obra está feita se possa deduzir o modo pelo qual ela queria ser feita' (1971:24). A tentativa de cunhar o termo traz subjacente uma problematização sobre a natureza e diversidade das potencialidades expressivas de uma cultura da manipulação de imagens ao vivo, estejam elas acompanhadas ou acompanhando sons. VJ: vídeo-jockey, visual-jockey ou vídeo-jamm? Depende do VJ e do lugar, mas será sempre jamming.

Os nomes trazem o entendimento do que vem a ser a atividade deste realizador e delineiam elementos estruturais da proximidade entre o meio expressivo e uma cultura urbana. A abreviatura surge nos anos 80 para designar apresentadores da MTV. Esta filiação nada diz da produção dos VJs em questão neste trabalho, mas nos interessam como curiosidade. Os VJs da MTV existem para uma emissora de televisão de música para jovens, os 'nossos' VJs tocam imagens para DJs, com DJs ou no contra-tempo dos DJs. Imagem e música estão aí imbricados. Os VJs da produção de imagens na cena eletrônica aproximam-se dos DJs e da televisão por acontecerem ao vivo e de improviso, mas deles se afastam por estarem atrás das telas e de computadores. Diferente dos VJs da MTV, não oferecem sua imagem persona, propõem imagens paisagens ou imagens jogos de associaçães de conceitos.

A denominação vídeo-jockey para o profissional da pista relacionase aos disk-jockeys. Enquanto os vjs tocam imagens previamente ordenadas em seqüências no computador, os djs se organizam a partir de discos e cds. $O$ vídeo dos VJs remete ainda a um suporte, o vídeo, é claro. Nos anos 90 usavam-se na pista fitas gravadas em vídeo. Hoje a saída da imagens pode vir diretamente do computador ou mesmo de DVDs. ODVD inicialmente foi uma tecnologia substituta do vídeo, um semelhante em termos poéticos. Hoje o DVD-J da pioneer possibilita a manipulação ao vivo das imagens com distorções criadas com scratches (mesmo procedimento dos djs) e acesso não-linear às imagens. Os DVDs-J e computadores possibilitam a projeção 
com temporalidades controladas pela mão do VJ. Instauram-se assim tempos e ritmos distintos a partir de um mesmo material. Não vamos nos deter em como a construção de uma temporalidade propõe sentidos pois este é assunto de outro artigo. ${ }^{2} \mathrm{O}$ que nos interessa reter no momento é que o vjing da cena eletrônica, jovem realização para jovens, tem pequena história marcada pela inscrição da técnica na poética.

Já a denominação visual-jockey costuma ser entendida no meio como uma qualidade específica da projeção onde predominam imagens abstratas e um ritmo acelerado, ou seja, um fluxo de imagens que cintila em velocidade. Se ampliamos a noção de visual para imagens em geral, conseguiremos abarcar de maneira mais completa a atividade do VJ. Visual é algo que diz respeito a ver, ao visivel, inclui imagens abstratas ou figurativas, produzidas a partir de algoritmos sem qualquer referência material externa, ou gravadas. Visual pode ainda ser uma imagem-luz, uma imagem-paisagem ou uma micro-narrativa construída por associação. Nesta perspectiva a sigla reitera a vinculação com a cena eletrônica, mas não se coloca estritamente vinculada a um suporte. e sim ao objeto produzido pelo VJ, imagens em suma.

Fora do Brasil são comuns as denominações Visual Performers e Visual Jammer. A última denominação novamente diz da imbricação entre música e imagem. A interpenetração sonoro-visual quando se pensa em jam, jamming ou jammer ${ }^{3}$ qualifica a poética do VJ. As jam-sessions. como muito bem sabem os admiradores deste gênero musical, são shows de jazz em que prevalece o improviso, e o jamming é o momento de improvisação nos shows. Jamming diz respeito a esta característica dos eventos com $\mathrm{VJ}$, o improviso, o ao vivo. Neste artigo não vamos nos deter no improviso, mas fica a título de lembrança a menção desta poética, da poética do ao vivot, no trabalho dos VJs. Resumindo, a atividade dos $\mathrm{VJs}$ diz respeito à manipulação de imagens fixas ou em movimento, figurativas ou abstratas, que são apresentadas em galerias de arte, em raves, em festas ou em boates, a partir de improvisações com um banco de imagens previamente selecionadas. Estas imagens. independente da sua origem técnica, existem com um acompanhamento musical. Acompanham ou são acompanhadas? Ambos são os movimentos como veremos adiante.

Experiências com projeções e manipulação de imagens não são uma ocorrência que se reduza aos dias de hoje. Pelo contrário, na história das vanguardas cinematográficas, como bem mostram Peter Weibel, Gene Youngblood e outros autores, são recorrentes trabalhos com projeções múltiplas. Yoko Ono, Laurie Anderson e os concertos do grupo Vortex realizaram nos anos 60 experimentos com diversas telas explorando ainda a divisão das telas. Gregory Markopoulos criou múltiplas projeções de diferentes filmes explorando a quebra da perspectiva central como alternativa de narração (Weibel. 2003:117). O casal Steina e Woody Vasulka. além de explorar o espaço 
com diversas projeções, aproxima-se da poética dos vjs por trabalhar ao vivo. Criam imagens e sons que passam por sintetizadores. Para não fazer da menção destes trabalhos uma citação desgastante e extensa demais lembro ainda, para concluir, que experiências como os panoramas nos séculos XVII e XVIII, ou mesmo diversas vanguardas de década de 20 do século passado com artistas como Lásló Moholy-Nagy desenvolvem uma poética próxima aos vjs. Ao quebrar a quarta parede do teatro italiano, criam para múltiplas projeções ou projeções impossíveis de serem visualizadas em uma única tomada do olhar, ou seja, com mais de cento e oitenta graus e em alguns casos suas performances e projeções acontecem ao vivo. A proximidade entre as poéticas das experiências acima citadas e dos vjs não anula particularidades na natureza destas formas expressivas. A cultura eletrônica, o espaço da experiência $e$ as imagens em relação com os sons e técnica em sua materialidade produtora de visualidade garantem ao trabalho dos vjs características poéticas que merecem ser exploradas.

\section{Alguns pactos}

Espaços-tempo, projeções e experenciador: senciente ${ }^{5}$ e sentido, visível e vidente se constituem na experiência. Festas, noite de estímulos multisensorial. $O$ espaço como aquilo que demarca o entre, existe aqui com visualidade material. O espaço entre é perceptível visualmente, e costuma ser branco, dada a grande quantidade de fumaça nele presente, seja resultado do cigarro ou de fumaça cenográfica. A fumaça é um recurso bastante utilizado no teatro e no cinema para materializar a luz, ela difunde a luz, faz com que seu feixe ocupe o ambiente, confira densidade a ele. Bem dosada, a fumaça é uma aliada na construção de uma cena, por conferir volume e peso ao espaço, difundir pessoas e objetos presentes, modificar os padrões de distância, pois perde-se com ela a profundidade de campo. Fumaça, luzes, projeções e sons criam o ambiente da festa, ambiente que envolve e estimula o espectador, reduz o espaço ao restringir o campo de visão, cria um ambiente circunscrito mesmo que haja no local centenas de outras pessoas, e produz assim uma espécie de cortina de fumaça. Este ambiente é constitutivo e constitui pactos com o público.

O mergulho em um livro de ficção, em um filme, em uma exposição, em um videogame ou trabalho de arte interativo pressupõe alguns pactos. Alguns priorizam aspectos ilusionistas, outros a manipulação física e intelectiva, outros um jogo ligado mais estritamente ao entendimento. Existem ainda trabalhos cujas propostas promovem o trânsito entre jogos estruturais intelectivos e de fruição ilusionista. No livro são o enredo e/ou a linguagem os elementos a estruturar o pacto. Alguns leitores se entregam ao mundo proposto, sua imersão/mergulho na história passando pela aceitação de um 
pacto constituído pela concentração nos sentidos na narrativa. Nesse sentido, a propriedade imersiva de um texto é um dos elementos intrínsecos de sua composição. ${ }^{6}$

Murray e Grau não nos deixam esquecer que a imersão é uma experiência secular. Murray usa a literatura, especialmente o Dom Quixote de Cervantes como exemplo de como um romance pode envolver os sentidos do leitor, pode colocá-lo no mundo representacional de maneira imersiva. Grau, ao longo do seu Virtual Art (2003), apresenta exemplos de ambientes imersivos, de ambientes ilusionistas experimentados ao longo dos séculos coletiva ou individualmente. Oliver Grau é radical ao atribuir à imersão um papel chave para se entender o desenvolvimento da mídia. O recorte privilegiado pelo autor é da relação do homem com a imagem (2003: 5), relação esta que constituiu o sentido da situação por meio da representação, ou no caso que nos interessa, por meio da constituição da presença (2003: 14), ou seja, a imersão opera entre a ilusão e a referência crítica externa, o que, de acordo com Grau. pode ser definido como o paradigma do meio (2003: 9). ${ }^{7}$

O meio é assim modelador de nossa percepção e é modelado por ela. Em uma relação de cruzamento de mão dupla, o espaço existe em função de como o percebemos e nossa percepção é por ele construída, digo, dirigida. $O$ espaço é um 'produto de complexos processos mentais' (Anders 2003:48) ou um 'construto mental que condiciona nossa relação com o mundo' (Anders 2003:49). O espaço é resultado de elaboração mental e hoje podemos experimentar materialmente espaços imateriais e espaços-imagens. Não se trata de passagens físicas no sentido de Benjamin, a cartografia convive com a iconografia, o sentido de presença se apresenta visualmente. A iconografia dos VJs nem sempre é narrativa.

O cinema, principalmente aquele que visa o grande público. é mestre em narrativas ilusionistas cujo pacto passa pela elaboração do enredo segundo técnicas e recursos expressivos da cinematografia. As vídeo-instalações e diversos trabalhos com performance são manifestações artísticas que têm um pacto próximo ao que os $\mathrm{VJ}$ s promovem. Estes pactos passam pela inclusão do espaço extra-campo da tela na poética. Não se trata de uma inclusão em termos narrativos, ou seja. acontecimentos de ordem diegética não são solicitados. Trata-se do espaço material temporalizado que cria uma situação para o senciente e constitui assim dois aspectos cruciais da poética, a disposição das telas, a quantidade de pessoas ali presentes em pé e a quantidade de luzes e sons constituem o objeto diante desta formalização espacial do acontecimento.

Nem sempre a dimensão e disposição das telas é suficiente para a constituição de um espaço de mergulho, principalmente nos eventos brasileiros produzidos e patrocinados por bebidas alcoólicas e energéticos. Predomina ainda o palco italiano, ou seja, todo o público voltado para uma única direção. Pode haver 
no palco um tríptico, ou uma tela central e pequenas televisões ao lado, ou mesmo telas cenográficas que se estruturam em formas, como foi o caso de uma tela do Skol Beats de 2004 que imitava uma geleira, mas ainda prevalece a projeção unidirecional. Nestes casos a fumaça, as luzes estroboscópicas e luzes coloridas fornecem ao ambiente uma imersão que poderia ser conseguida também com as telas, maximizando-șe o papel das projeções no conjunto dos elementos utilizados para se montar o espaço.

No Brasil, poucas instituições artísticas, como galerias e festivais de arte eletrônica, abrigam VJs. Mas o investimento nos projetores ainda é modesto em.termos de quantidade, qualidade e potência. A proposta mais completa foi organizada em 2002 por Luiz Duva, Fabiana Prado e Tatiana Lohmann. Foi o primeiro e único Festival brasileiro de VJs, o RedBull Live Images. Este evento é exemplar das condições ideais de trabalho devido à sua montagem. Participaram os pioneiros do gênero no Brasil: de São Paulo os VJs Spetto, Aléxis, Palumbo, Duva, Raimo e os coletivos Bijari e Embolex; do Rio de Janeiro, Lucas Margutti, Jodele Larcher, e de Minas Gerais o coletivo FAQ $^{8}$.

Em um galpão havia nove projetores lançando suas imagens em telas de tảmanho distinto, o público rodeado por elas. Havia três ambientes com intercomunicação visual e física. Ao caminhar ou dançar, telas inteiras e/ou pedaços da tela ficavam disponíveis à visualização. $\mathrm{O}$ tamanho das telas e pedaços das imagens acessíveis ao olhar dependia do posicionamento do

160 observador. Se o espectador estivesse situado na "sala" central, estava circundado por quatro telas quadradas. A sala tinha duas passagens para outros ambientes. Da mais estreita podia ser visto um telão e na outra, mais ampla, havia telões dispostos verticalmente de modo a formar uma espécie de torre. Mais adiante, a noventa graus, em uma parede um pouco mais afastada, uma tela maior cobria toda a parede.

A estimulação constante pelas luzes das projeções, pela música, pelas imagens cintilando e pessoas em profusão circulando a pé criava um ambiente dispersivo e de estimulação retiniana. A projeção disputava com todos estes elementos, mas como a quantidade de telas era grande e, como dissemos, suas dimensões variadas, elas estavam sempre disponíveis ao olhar, algo sendo exibido em qualquer direção. Em festas em geral, a imagem se impõe não apenas em função daquilo que mostra. Em alguns momentos chama muita atenção a ponto de provocar uma reação do público, em função do ritmo e estimulação que provocam, tanto pela velocidade na manipulação quanto pela natureza da imagem.

O espaço se consolidava, ganhava características específicas em função do VJ que se apresentava. A natureza do trabalho, suas cores, sua proposta criavam o ambiente, solicitavam movimentação espacial determinada em função da proposta da projeção. Assim, o espaço físico onde estavam as 
pessoas e as projeções, e o espaço da projeção em si, digo dos telões, se faziam presentes no conteúdo das imagens, alterando a perspectiva privilegiada na apresentação. Isso era resultado tanto da velocidade impressa à imagem, quanto das cores e da relação de conteúdos entre as telas. Uma imagem passa, tão rápido - difícil afirmar sua função, seu contorno, em uma primeira visada - e volta associada com outra, agora permanece por mais tempo, mas mesmo tendo sua permanência aumentada ainda escapa, alguém passou, a fumaça a difundiu. A falta da imagem, daquela imagem e sua companheira seqüencial passa a funcionar como uma espécie de solicitação para o ver.

No Festival Live images a maneira como as telas eram visualizadas criava uma composição de modo a permanecer no campo de visão uma tela inteira e pedaços de outras. Os pedaços funcionavam como um detalhe, ampliação do todo. O tamanho da tela altera a percepção do movimento, em telas maiores o movimento parece mais lento. Neste caso convive-se com imagens, manipuladas na mesma velocidade e que, devido ao tamanho da tela, trazem temporalidades distintas. O efeito causava estranhamento ao senciente e o tempo de evolução da imagem imprimia sentidos temporais e intensidades variadas à imagem e som. O tamanho e localização espacial da imagem alterava sua força e suavidade e havia ainda um diálogo propiciado pelo tempo inscrito pela multiplicação das imagens em distintas telas.

No trabalho Vermelho Sangue, de Luiz. Duva, a variação na sucessão da imagens gerava intensidades de violência e afeto. Havia ainda uma sobreposição intrigante das imagens. A cena projetada era a mesma, assim como a situação apresentada em cada tela. Os cortes e fusões realizados eram sincrônicos, mas pareciam diferentes, carregando temporalidades de movimentos distintos. A repetição deixava de ser redundância, poucos elementos e cores produziam choques visuais e se mostravam diferentes. Sensações e idéias sobre a situação se agregavam à cena projetada em função da repetição. A cena de amor era afetiva ou ríspida. algumas vezes afetiva e ríspida simultaneamente em decorrência da manipulação. Por exemplo o pequeno gesto de um pé em uma poça de sangue crescia pela velocidade do pé. Em um primeiro momento rápido, depois permanecia praticamente parado. lento, suave. Os ritmos e intensidades distintos reproduziam o mesmo como diferente, a temporalidade funcionando como comentário da sequiência já vista. Como lembra Merleau-Ponty, a percepção é aquisição de conhecimento pelos sentidos, o que é um fenômeno da consciência. A repetição das imagens. com telas e tempos distintos, imagens de amor dolorido. nos informam sobre as próprias imagens projetadas.

Já o coletivo Bijari, formado por arquitetos, explorava o espaço urbano tanto em sua temática quanto no uso do galpão. Além da projeção eles realizaram uma performance com atores e levaram ao local vendedores de 
pipoca e de maçãs do amor. Aí estamos no campo das performances semelhantes às praticadas nos anos 60 . Músicos fantasiados com roupas tribais aumentavam a diversidade de tipos humanos, criavam obstáculos na pista. Da mesma maneira que não é comum em festas com música eletrônica a presença de ambulantes que vendem pipoca e maçã do amor, tampouco é corriqueira a presença de um músico fantasiado com peruca, roupa cáqui e tocando tambor.

Nas projeções a cidade era paisagem. Ícones urbanos à nossa volta se sobrepunham a travellings de ruas da cidade, travellings longuíssimos jogavam o público no trânsito de São Paulo, os personagens na pista provocavam o choque físico sugerido pela imagem. Eles se moviam de um lado para outro aumentando os choques entre as pessoas e a necessidade de atenção sobre o posicionamento físico naquele espaço. A velocidade dos carros mudava. Frases e ícones entravam colocando de maneira solta questões relativas ao espaço urbano. As telas tinham mais de um movimento simultaneamente. Há elementos expressivos que não têm uma relação tão estreita com o espaço físico, mas nele acontecendo. Na situação em que aconteceram funcionavam com a dispersão e com o ritmo do ambiente.

O trabalho de Duva propõe ao espectador uma imersão silenciosa, o do Bijari simula o universo urbano e solicita atenção semelhante à demandada em uma cidade. Parece paradoxal, mas é uma imersão de atos, produzida como resposta ativa à situação. Será que a imersão consegue abarcar essa 162 diversidade de situações? Em tese acreditamos que sim, como se verá adiante.

Uma das marca do trabalho realizado ao vivo é sua relação com a pista. Mesmo previamente definida, a sequiência dos sets de imagens dependerá do grau de atenção ou dispersão da pista. Fatores como a hora da noite em que o VJ entra, o que implica uma maior atenção ou não por parte do público, determinam o material a ser trabalhado e o como. VJ Spetto fala em temperatura de pista como metáfora para o clima local. Temperatura de pista é uma expressão proxima à temperatura de cor, mas aqui se procura um tipo de tom, cor, ritmo e qualidade visual para se constituir um ritmo de fruição, é uma evolução de estímulos criando uma partitura visual. Em suma, o que projetar, quando projetar, o momento de retirar a imagem e deixar apenas a cor branca ou uma cor qualquer relaciona-se à construção do ritmo com o público. $\mathrm{O}$ modo como está a atenção do público, a quantidade de gente ali presente e a música tocada vai criar a experiência imersiva. Assim temos um pacto coletivo, uma construção coletiva de um espaço-tempo.

Os exemplos acima colocadọs -literatura, internet, pistas - falam de situações, de espaços e de projeções bastante distintas. Haveria neles a imersão? Tem sido afirmado que sim. Então o que vem a ser imersão? Vamos conceituar nosso entendimento de imersão, de espaço e o seu uso na arte como estrutura significante, ou não. 


\section{Imersão e espaço: noções imbricadas}

A idéia de imersão tem sido usada de maneira recorrente nos últimos tempos. Seu uso "eneralizado relaciona-se à proliferação de espaços imateriais propiciados pelo computador. Estes espaços estão presentes em videogames. em representações na arte, na arte virtual, em espaços manipuláveis como na telepresença ou em protótipos de máquinas industriais e aviões passíveis de serem conhecidos através do computador. Mas não é apenas um termo que se revitaliza, é uma discussão subjacente ao espaço, material ou não. e nossa relação com ele. A imersão passa necessariamente pelo contato do corpo físico e do corpo-sentidos com o meio em que se localiza o observador. Os espaços físico e imaterial organizam nossa percepção de maneira a se complementarem ou estabelecerem atritos quando nos dedicamos a atividades mediadas ou promovidas por estas máquinas. Novas noções e experiências de espaço somam-se ao espaço tradicional, ou seja. ao espaço físico consolidado. Vivemos a ampliação de espaços ilusionistas, físicos ou não, e a invenção de espaços imateriais funcionando como interfaces para espaços materiais ou para experimentações que num futuro se tornarĩo objetos. máquinas, etc. As trocas e a percepção resultantes do convívio com os computadores e espaços a eles contíguos tem seus termos definidos por pactos ilusionistas por nós construídos.

Tanto as noções de imersão quanto as de ilusão e ilusionismo trazem um atrito ao estabelecer um jogo, uma tensão, uma negociação entre o sensível e inteligível. Janet Murray lembra o sentido metafórico de imersão. É uma imagem da experiência de submergir na água, um acontecimento da ordem da experiência que produz a sensação de se estar circundado por outra realidade. que toma toda a atenção do nosso aparelho de percepção (1997: 98-110). Para Oliver Grau a imersão é um conceito algumas vezes "opaco e contraditório" pois proporciona uma experiência complexa e multifacetada dependente da posição do observador (2003: 13). Grau coloca ainda a imersão como um processo estimulante intelectualmente. ao mesmo tempo uma mudança, um processo de absorção mental em que há trânsito de um estado mental a outro. caracterizado pela distância crítica em relação ao que está sendo mostrado. e o crescimento emocional naquilo que está acontecendo (2003: 13).

A imersão pode assim ser entendida pelas colocações de Murray e Grau como uma zona de instabilidade dos sentidos. Zona de instabilidade de preceitos estritamente racionalistas. Zona de sensorialidade, de sinestesia, região de trânsito capaz de proporcionar insigths e propiciar a construção de descobertas. Mais, ou menos. dirigida em função do evento no qual é promovida. a imersão é experiência de relações multifacetadas. Um ambiente físico ou intelectual envolve a pessoa de tal modo que ela mergulha em outra realidade, produz outra poética. sem abrir mão por completo de suas referências 
mais concretas. Murray (1997: 110) coloca em sua análise de videogames e da imersão ali vivenciada que o jogo se dá no trânsito entre a entrega e o questionamento ao meio, ou seja, o cognitivo reforça em vez de questionar a realidade da experiência. O pacto ilusionista pressupõe a aquiescência do cognitivo.

\section{Espaço-luz. Espaço-som.}

As situações, eventos, lugares e imagens aqui apresentados em alguns momentos podem sugerir perspectivas de análise da sociologia urbana ou da antropologia. Os campos do conhecimento mencionado caberiam caso a ênfase do trabalho fosse como o espaço organiza e propicia um determinado tipo de apropriação dos elementos expressivos. A cultura advinda da cena eletrônica é de extrema relevância para esta análise no que diz respeito a como ela promove uma poética perceptiva. As músicas, as imagens, as luzes, enfim o local das projeções, são de fluxo de imagens, de luzes e de sons que vêm corroborar a constituição de uma experiência de percepção onde o terceiro olho de Merleau-Ponty (1980:90), aquele olho que vê as imagens materiais e mentais oscila entre a pista e a tela.

Ao buscar as festas, o público está interessado em uma experiência de entretenimento, uma fruição estética e artística que lhes provocará estímulos. Estes estímulos são também acionados pelo consumo de estimulantes químicos e bebidas alcoólicas. Há uma busca de prazer que se aproxima das propostas analisadas por Gene Youngblood ${ }^{9}$ no seu Expanded Cinema. $\mathrm{O}$ apelo místico e esotérico das raves, a proposta de se alcançarem outros estágios de consciência, também eram o apelo de alguns realizadores estudados por Youngblood. Se a experimentação mística desapareceu, ainda prevalece nos discursos de alguns VJs a proposta de desenvolverem trabalhos que vão ter o seu sentido apreendido num momento posterior, ou seja, há aí uma menção a processos de associação. As imagens, por seu grau de abstração e velocidade, perturbariam a percepção do dia a dia. $\mathrm{O}$ que nos interessa reter destes discursos, é o tipo de pacto proposto. Este extrapola o ilusionismo assentado em regimes de visibilidade narrativa.clássica e racionalista. Ultrapassa, por exemplo, o pacto da mera suspensão da descrença - tão discutido em teoria literária - exigido do fruidor para que a inteligibilidade do texto, do filme, da peça, i.e., da obra de ficção seja garantida. Mesmo em trabalhos com imagens figurativas o pacto é de experimentação sensorial, de vivência. É o mergulho coletivo em um ritmo visual e sonoro. Mais que uma extensão, é uma exacerbação dos pactos tradicionais, mas é, contudo, ainda um pacto, sem o qual nenhuma vivência criará o registro poiético.

O trabalho com múltiplas projeções dos VJs e com um fluxo e pulsação de imagens, de gráficos e de luzes é mais próximo do videoclipe do que do 
cinema figurativo. Tanto a evolução da imagem quanto sua vinculação direta com o som, no sentido de acompanhar ou ser por ele acompanhado, dizem respeito a outro regime audiovisual. Arlindo Machado aponta caminhos para pensarmos esta cultura como tendência da produção contemporânea em que sua estrutura não é imagem ou som, só pode ser entendida em termos do audiovisual, ou de uma 'estrutura motovisual'.

\begin{abstract}
“As imagens do clipe têm sido tão esmagadoramente contaminadas pelas suas trilhas musicais, que acaba sendo inevitável sua conversão em música, isto é, numa calculada. rítmica e energética evolução de formas no tempo. Nesse sentido, pode ser muito útil observar como o clipe está evoluindo de um mero adendo figurativo da música para uma estrutura motovisual" ${ }^{10}$ que é, ela também, em essência. de natureza musical". (2000: 178)
\end{abstract}

Ela é de natureza visual tanto pela evolução, como coloca Machado, quanto por nos tocar de frente, pelas costas ou de lado, por cintilar e refletir. DJs e VJs constroem um todo rítmico sonoro e visual. Pode haver complementaridade, quando os dois funcionam em ritmos semelhantes, ou ao contrário, cada um dos dois segue caminho próprio e em alguns momentos se unem. É a 'estrutura motovisual', sincronia e/ou assincronia sincopados. Som e imagem não podem ser pensados separadamente, são simultâneos e interligados, são audiovisão". Se imagem e som forem entendidos como partes de uma partitura, o ponto de fuga pode estar ora em um, ora em outro. Como as manipulações da imagem e do som se dão ao vivo, é a partir do jogo entre os dois que acontece a montagem, que se estabelece o ritmo como um todo e se desenha um espaço.

Marcos Novak define seu trabalho na internet como "um processo de metamorfose onde há uma sinfonia do espaço" (2002: 273). Consideramos que na pista, no ambiente material também há uma sinfonia. $\mathrm{O}$ ambiente funciona como partitura, ou seja, organiza a composição do espaço pela construção de um ritmo de audiovisão, pela invenção de um espaço, pela invenção do espaço-imagem. Chris Musgrave ${ }^{12}$ sugere que seu trabalho deve ser visto em um ambiente com o som reforçado e escuro. "Mregh-u-linea" de Musgrave é ambiente audiovisual. Em um tríptico ele cria uma evolução de figuras geométricas. Inicialmente brancas, trazem pequenas explosões sonoras e visuais condutoras da evolução da música e da imagem. A música marca o crescimento da imagem que esquenta, fica alaranjado-terra, do alaranjadoterra vai ao azul anil. As cores e formas sangram, não respeitam os limites da tela. As primeiras imagens se parecem a geleiras, as intermediárias a fogo. Scott Pagano ${ }^{13}$ reestrutura o espaço físico onde se dá a cena ao criar uma desordem visual pela mescla de janelas de edifício que dançam à nossa frente. 
As cidades, as luzes, os ícones da cultura urbana, os borrões e os slogans se substituem em maior ou menor velocidade, mas acima de tudo evoluem como tons musicais. Crescem e diminuem em tensão, pára a imagem, o tempo fica suspenso, a música segue outro ritmo. Somos levados para uma cidade inexistente. Produto de paisagens em tese familiares, difícil de se ter certeza sobre o conhecimento da mesma, afinal a maioria dos exemplos de fachadas pode existir em diversas cidades. A cidade material cede lugar à poesia da cidade ali criada. A imagem parece musical, a música soa visual. Sinestesia? Também, mas fica-se entre, entre os espaços imaginários vistos e os relembrados ali. Entre luzes, entre imagens, entre sons, entre pessoas, entre a certeza de se estar em uma festa e a experiência de visitar paisagens pessoais e físicas imaginadas:

O cineasta francês dos anos 20 Marcel L'Herbier definiu o cinema como a "música da luz". A cena eletrônica dos VJs produz a música da luz na raiz, ou seja, a luz estimulação-cor, a luz-matéria que sofre refração no encontro com os corpos físicos, humanos ou não. A imagem luz que diluída no ambiente e rebatida ganha poderes semelhantes ao som, é vista-sentida mesmo quando não olhamos para ela diretamente. É a imagem luz para ser lida em um regime de visibilidade que pode ou não incluir significados. É uma luz estímulo. Cada época tem uma cultura visual, um regime de visibilidade. $O$ nosso inclui a audiovisão, produz estímulos motovisuais. Os sons por sua vez, como já dissemos, ganham uma materialidade visual.

166 Os exemplos priorizaram trabalhos não-figurativos, trabalhos abstratos. Mesmo quando existe um tema, quando o realizador se propõe a apresentar conteúdos com referências materiais explícitas, ou quando há uma apropriação de imagens da TV, do cinema, etc, há um grau de abertura nas projeções que ainda nos autoriza a pensar em termos de partituras visuais. Nem toda noite ou festa é feliz em seus propósitos. Cada dia temos visto trabalhos piores, que nada dizem e que nenhum apelo proporcionam, mas isso faz parte de toda e qualquer atividade humana, não merece menção.

\section{Notas}

${ }^{1}$ Este artigo contou com a contribuição generosa de Julio Pinto. São dele as sugestões da semiótica e do uso das noções de Leitor Modelo e Leitor Implícito de Eco e Iser. Não tenho palavras para agradecer a interlocução fina e inspirada de Julio.

${ }^{2}$ Esta citação foi utilizada por Rodrigo Fonseca e Rodrigues, relator de uma primeira versão deste texto no encontro da Compós de 2005, GT Criação e Poéticas Digitais. A ele agradeço muito. Agradeço as criticas e o Pessoa presenteado em seu relato belo e preciso. 
${ }^{3}$ Esta questão foi discutida em texto apresentado na Compós de 2004 pela autora denominado : A montagem dos VJs: entre a estimulação ótica e a física"

"vjamm é também um software da audiovisualizer desenvolvido para o vjing.

${ }^{5}$ A noção Poética do ao vivo encontra-se no Livro Obra Aberta de Umberto Eco e no texto A Poética do ao vivo de Arlindo Machado(2000). os dois autores estão discutindo a TV.

${ }^{6}$ Noção proposta por Merleau-Ponty. Paradoxo produtivo em que aquele que sente e pensa se constitui no encontro, na percepção em um espaço-tempo determinado.

${ }^{7}$ Isso é dito inclusive em analogia com propostas como as de Leitor Modelo e Leitor Implícito apresentadas por Eco e Iser. Ambos são elementos constitutivos dos textos.

${ }^{8} \mathrm{Um}$ modo semiótico de entender essa relação é correlacionar a representação com as instâncias de poder objetal, isto é, espaços em que o signo faz referência forte a seu objeto (como no caso dos ícones, índices e símbolos). Peirce talvez dissesse que, no caso de uma estética $\mathrm{VJ}$, teríamos o signo não mais em sua iconicidade, por exemplo, mas em sua qualissignidade, isto é, muito mais como presença qualitativa do que como instância de remessa anafórica a um objeto externo. O signo apenas está lá, no meio.

${ }^{9}$ Para informações sobre os grupos e VJs procurar em www.vjing.com.br nas secções Perfis e Entrevistas.

${ }^{10}$ Não cabe nas poucas páginas deste ensaio discutir estas questões. São complexas e não concordamos com elas completamente. Como já dissemos o que nos interessa é fazerem parte de uma cultura que estabelece pactos de fruição, de percepção onde não cabe o ilusionismo reduzido à tela, há uma proposta de experimentação multi-sensorial que mergulha o público no ambiente com requisitos de outra ordem.

"Grifo nosso.

${ }^{12}$ Título de um livro de Michel Chion, pesquisador francês do design sonoro no cinema.

${ }^{13}$ Coletânea de VJs e videoartistas denominada reline. www.reline.net

${ }^{14}$ www.reline.net

\section{Referências}

ANDERS, Peter. Ciberespaço antrópico: definição do espaço eletrônico. In: DOMINGUES, Diana. Arte e vida no século XXI. Sp: Unesp. 2003.

CRARY, Jonathan. Techniques of the Observer: On vision and modernity in the ninteenthcentury. 9th edition. Cambridge, Massachusetts: MIT press. 1999.

ECO, Umberto. Obra Aberta. 2a ed. SP: Perspectiva. 1971. 
GRAU, Oliver. Virtual Art. From Illusion to Immersion. Cambridge, Massachusetts; MIT Press. 2003.

MACHADO, Arlindo. Reinvenção do videoclipe (173/196). In: A televisão Levada a sério. SP:editora Senac. 2000.

MERLEAU-PONTY, Maurice. Fenomenologia da percepção. $2^{\text {a }}$ ed. SP: Martins Fontes. 1999.

O olho e o espírito. In: Os

Pensadores. SP: Abril Cultural. 1980.

MURRAY, Janet H. Hamlet on the Holodeck. The Future of

Narrative in Cyberspace. Cambridge, Massachussetts: MIT Press. 1997.

NOVAK, Marcos. Liquid Architectures in Cyberspace. In: PACKER, Randall e JORDAN, Ken. Multimedia. From Wagner to Virtual Reality. New York, London: Norton \& Company. 2002.

WEIBEL, Peter. Expanded Cinema, Video and Virtual Environments. In: Future Cinema. ZKM. 2003.

YOUNGBLOOD, Gene. Expanded Cinema. NY: E.P. Dutton \& CO., Inc. 1970. 